\title{
Research Article Properties of The Water-Based Paint Mixed With The Purple Bacteria
}

\section{Byungcheol Choi and Insoo Kyoung and Sangsoo Lee*}

Master`s Course, Dept. of Architectural Engineering, Hanbat National University, 34158, S. Korea

Docter`s Course, Dept. of Architectural Engineering, Hanbat National University, 34158, S. Korea

*Professor, Dept. of Architectural Engineering, Hanbat National University, 34158, S. Korea

*Corresponding author. Tel.: +10-3324-3992; Email address: sslee111@ hanbat.ac.kr

Article History:Received:11 november 2020; Accepted: 27 December 2020; Published online: 5 April 2021

\begin{abstract}
Recently, as carbon dioxide emission increases, global warming is rapidly progressing, and indoor air quality is also affected. In this study, a functional paint was prepared by mixing purple bacteria in an water-based paint, and carbon dioxide adsorption, alkali resistance, and impact resistance were tested. The mixing ratio of purple bacteria is set to $0,5,10$, $15(\%)$, and the carbon dioxide adsorption experiment is divided into the case of no light and the case of light. As a result, In the absence of light, complete sealing is achieved as the carbon dioxide concentration in the empty chamber according to the mixing ratio of purple bacteria is considered to be kept constant as $100 \%$. The carbon dioxide concentration of the paint without the purple bacteria was higher than that of the purple bacteria. In the case of light, the decrease of the carbon dioxide concentration tended to be more active than in the case of no light. There was no difference in alkali resistance and impact resistance when comparing the paint without the purple bacteria and the paint mixed with it. In addition, there was no difference even when the incorporation rate of purple bacteria increased. Finally, as for the viscosity, the faster the fall time of the paint, the lower the viscosity of the paint, and the drying time, the lower the viscosity of the paint, the longer the drying time. Therefore, It is believed that water-based paints mixed with purple bacteria can improve indoor air quality by adsorbing carbon dioxide.
\end{abstract}

Keywords: Carbon dioxide, Purple bacteria, Water-based paint, Adsorption, Indoor air quality.

\section{Introduction}

As shown in [Figure 1, 2], as the seriousness of global warming has recently emerged, environmental movements to reduce carbon emissions are being carried out at a global level. Carbon dioxide is a problem that must be solved even in the construction industry, which accounts for more than a quarter of national energy and resource consumption, and new technologies are developed through various researches and environmental impact assessment methods are being conducted. In addition, as buildings are closed as they enter the modern society and people's interest in the environment increases, interest in indoor air pollution is increasing, and carbon dioxide is a factor that degrades indoor air quality. As a solution to this, purple bacteria can reduce carbon dioxide through photosynthetic action, but it is mainly used for agriculture, livestock, and fisheries, so research in terms of materials is insufficient $[1,2,3,4,5,6,7]$. Therefore, this study aims to produce functional paints using purple bacteria to reduce carbon dioxide emissions and present them as basic research data to examine the practical use of functional paints.

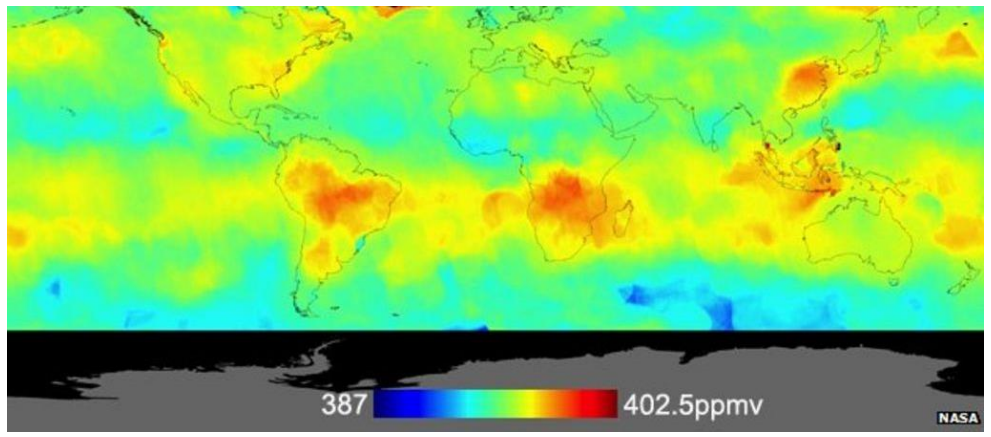

Figure 1 Averaged carbon dioxide concentration in 2014 (source : BBC news)

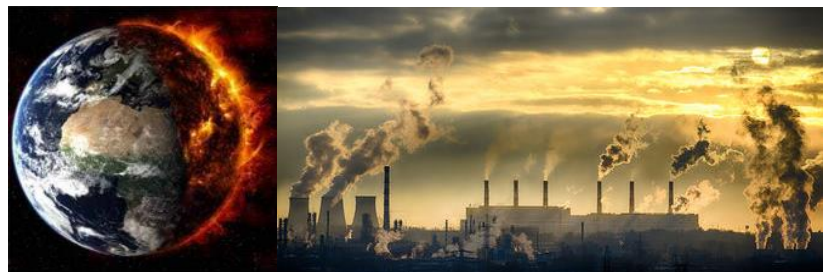

Figure 2 Global warming and carbon dioxide emissions (source : climateandcapitalism / sciencemag)

\section{Experimental plan}

*Corresponding author: Sangsoo Lee

Professor, Dept. of Architectural Engineering, Hanbat National University,

34158, S. Korea . Email address: sslee111@hanbat.ac.kr 
This experiment derived the maximum incorporation rate using purple bacteria. Then, after selecting a comparable mixing ratio within the maximum mixing raio range, carbon dioxide adsorption, alkali resistance, impact resistance tests, viscosity, and drying time experiments are conducted. As for the experimental factors and levels, as shown in [Table 1], the incorporation rates of purple bacteria were selected as $0,5,10,15(\%)$, and the curing conditions were dry curing. The criterion for dividing the range of the mixing ratio of purple bacteria was that when the paint containing purple bacteria was visually observed, the degree of plastering and viscosity was judged to function as paint up to $15 \%$, and when it exceeded $15 \%$, it showed the same viscosity as water to be.

Table1 Experimental factors and levels

\begin{tabular}{cc}
\hline Experimental factor & Experimental levels \\
\hline Paint type & Internal water-based paint \\
Mixing ratio of purple bacteria & $0,5,10,15(\%)$ \\
Curing conditions & Dry curing \\
Test items & Carbon dioxide adsorption, Alkali resistance, Impact resistance, \\
& Viscosity, Drying time \\
\hline
\end{tabular}

\subsection{Materials}

\subsubsection{Purple bacteria}

It is a fungus belonging to inorganic nutrients that can synthesize organic nutrients necessary for development from inorganic substances in the environment, and absorbs light energy and uses carbon dioxide as a carbon source. The photosynthetic bacteria used in the study (purple bacteria), as shown in [Figure 3], form water and organic matter without consuming oxygen by receiving light energy from carbon dioxide and hydrogen. The viable cell count of this product contains $4.0^{*} 10^{7} \mathrm{cfu} / \mathrm{ml}$ and is a bacteria that prefers anaerobicity[1,3].
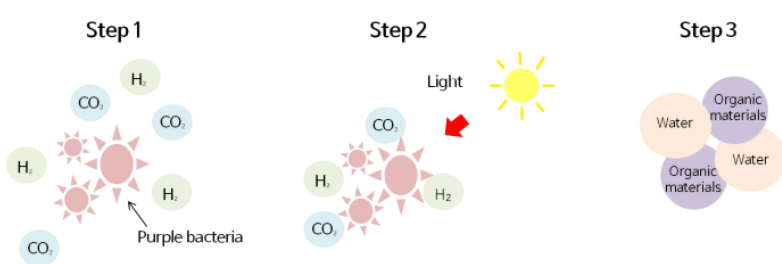

Figure 3 Purple bacteria adsorption mechanism

\subsubsection{Water-based paint}

Paint is a chemical product in a fluid state that gives the object the desired performance by applying it to the surface of an object to form a dried film layer. The paint used in this study used 88-Tex 2000 Grade 2, a waterbased paint for interior use, and the color was white, and the volume solid was 88 Tex 2000 Grade 2 (43.1\%), and the dilution rate was water. It can be diluted up to $5 \% \cdot[8,9,10]$

\subsection{Experimental methods}

\subsubsection{Carbon dioxide adsorption test}

A 100x100x40 (mm) test sample is placed after maintaining a constant standard carbon dioxide concentration in a sealed empty chamber of a functional paint containing purple bacteria. Next, it is measured using a carbon dioxide concentration meter (ISR-5000). The measurement time was 2 hours and the concentration was checked every 20 minutes. When measuring adsorption, it is carried out in two cases: light and no light. [Figure 4] shows the adsorption test method.

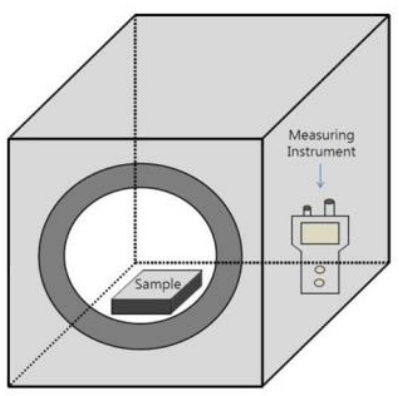

Figure 4 Adsorption test 


\subsubsection{Alkali resistance test}

For alkali resistance, paint and cure a functional paint containing purple bacteria on a 150x50x30 (mm) test specimen according to KS F 4715 (thin finishing wall coating material), and then paint and cure the back and sides with epoxy resin paint. . The cured test sample is filled with a saturated solution of calcium hydroxide at $20 \pm 2^{\circ} \mathrm{C}$ to a height of about $90 \mathrm{~mm}$ in a beaker, and the test sample is immersed vertically for about 24 hours. After 24 hours, take out the test specimen, wipe it dry, and after drying in an air-dry condition for 3 hours, visually check the presence or absence of fine cracks, deformation, swelling, peeling, and melting, and compare it with the part not immersed in the test solution. [Figure 5] shows the alkali resistance test method.

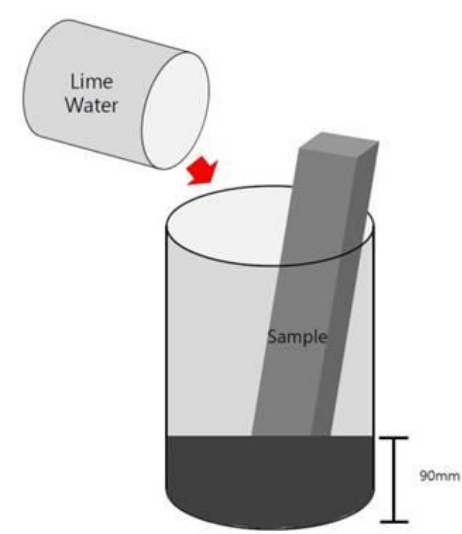

Figure 5 Alkali resistance test

\subsubsection{Impact resistance test}

For the impact resistance, a test body 300x300x60 (mm) was produced according to KS F 2221 (Impact test method for building boards), and a functional paint mixed with purple bacteria on the test body was painted and cured, followed by repainting and curing. The impact resistance test is measured by dropping a weight of $500 \mathrm{~g}$ from a height of $30 \mathrm{~cm}$ based on the upper surface of the test object based on KS F 4715 (thin finishing wall coating material). This test is carried out in 3 places more than $5 \mathrm{~cm}$ apart and visually checks for fine cracks, swelling, deformation and peeling. [Figure 6] shows the impact resistance test method.

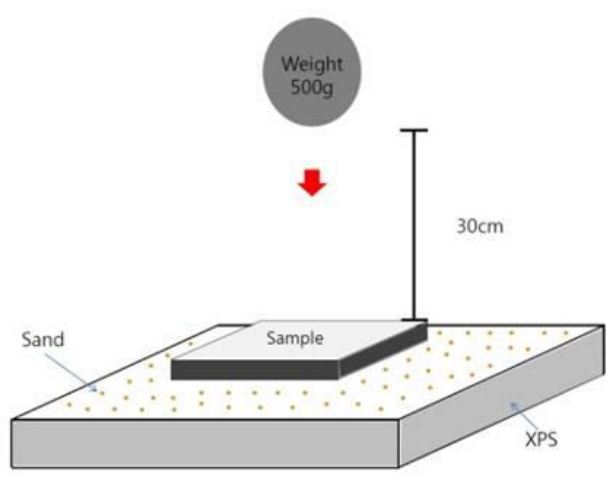

Figure 6 Impact resistance test

\subsubsection{Viscosity}

The viscosity test method of the paint is carried out as a simple experiment as shown in [Figure 7]. The mass of the paint is set to $50 \mathrm{~g}$ and the drop height is $30 \mathrm{~cm}$. Put the paint in a cup and drop it, and measure the time when all the paints have fallen. 


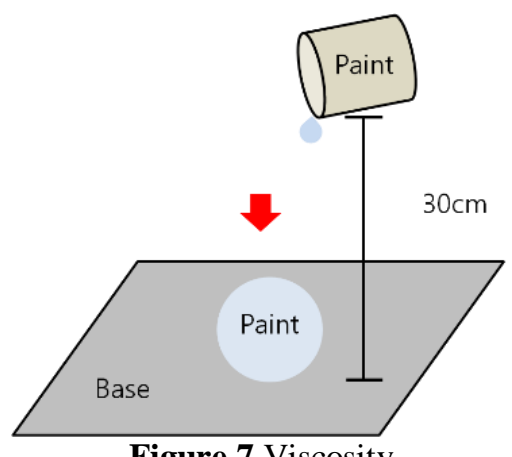

Figure 7 Viscosity

2.2.5 Drying time(full hardness)

For the drying time of the paint, a simple experiment is conducted in accordance with KS M 5000 (test method for paint and related raw materials). Full hardness is considered full hardness if the coating film is scratched with a fingernail or a knife tip and feels that it is hard and hard to scratch.

\section{Experimental result and analysis}

\subsection{Carbon dioxide adsorption}

[Figure 8] shows the results of adsorption experiment according to the mixing ratio of purple bacteria in the absence of light. The empty chamber is completely sealed as it is kept constant when the reference carbon dioxide concentration is $100 \%$. In the case of purple bacteria incorporation rates of $0,5,10$ and $15(\%)$, the reduction in carbon dioxide concentration is $37.8,27.7,29.9$, and $35.0(\%)$, respectively, and the reduction trend is not clear. In addition, the carbon dioxide concentration of the paint without the purple bacteria was higher than that of the purple bacteria. This is thought to be due to the fact that the purple bacteria exhale carbon dioxide by respiration. [Figure 9] shows that in the case of light, as in the case of no light, the reference carbon dioxide concentration in the empty chamber is constant, and the carbon dioxide concentration decreases as the mixing ratio of purple bacteria increases. Purple bacteria 0, 5, and $10(\%)$ reduced the carbon dioxide concentration by 51.7, 54.6, and $55.2(\%)$, respectively, and from $15 \%$, the carbon dioxide concentration decreased by $66.7 \%$. In the case of light, the decrease of carbon dioxide concentration tended to be more active than in the case of no light.

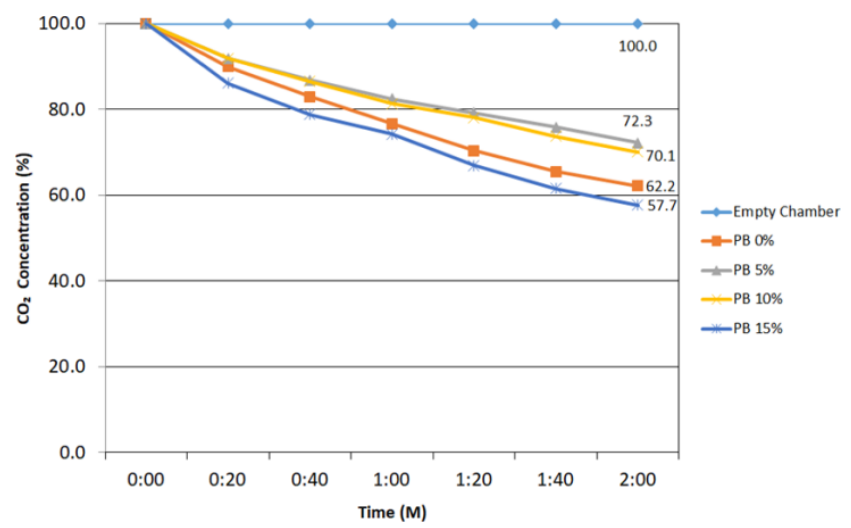

Figure $8 \mathrm{CO}_{2}$ concentration relative to initial concentration (No light) 


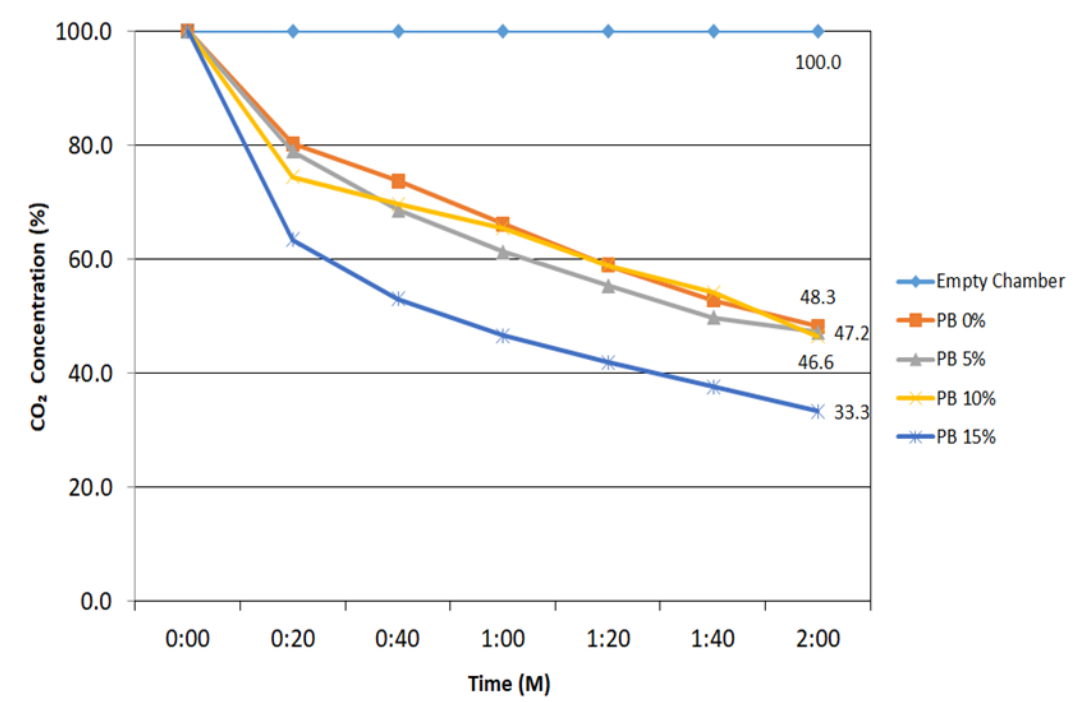

Figure $9 \mathrm{CO}_{2}$ concentration relative to initial concentration (light)

\subsection{Alkali resistance}

[Figure 10] shows the alkali resistance test according to the mixing ratio of purple bacteria. Based on the straight line in [Figure 10], the left side is the part dipped in calcium hydroxide solution and the right side is the part not soaked. Paints that did not contain purple bacteria did not show swelling, deformation, fine cracking, or discoloration. In addition, swelling, deformation, discoloration, and fine cracking did not occur in all three cases in which 5, 10, and $15(\%)$ were added. When comparing only the alkali resistance, there is no difference between a paint containing purple bacteria and a paint without mixing.

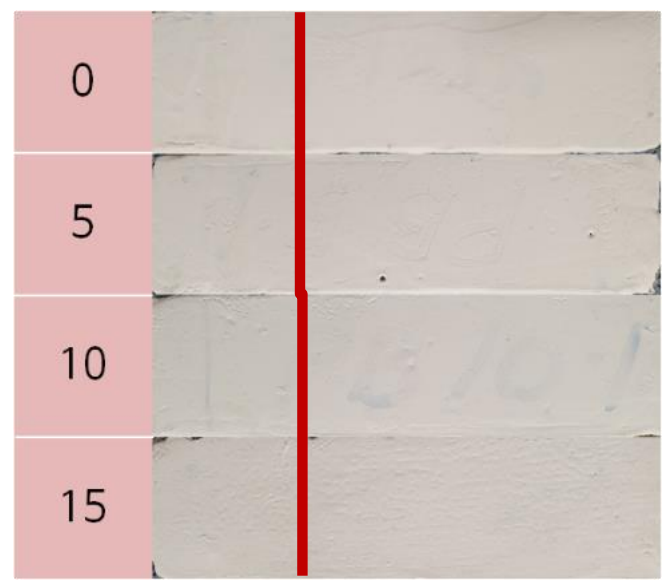

Figure 10 Alkali resistance according to the mixing ratio of purple bacteria

*

\subsection{Impact resistance}

[Figure 11] shows the impact resistance test according to the mixing ratio of purple bacteria. When the paint that did not contain purple bacteria was observed with the naked eye, it was confirmed that the place where the weight was dropped was hollow. When 5, 10, and $15(\%)$ were added, in all three cases, the degree of depression was similar to that of the paint without mixing purple bacteria. In addition, fine cracking and swelling did not occur. When comparing the impact resistance alone, there is no difference between the paint containing the purple bacteria and the paint without the addition. 


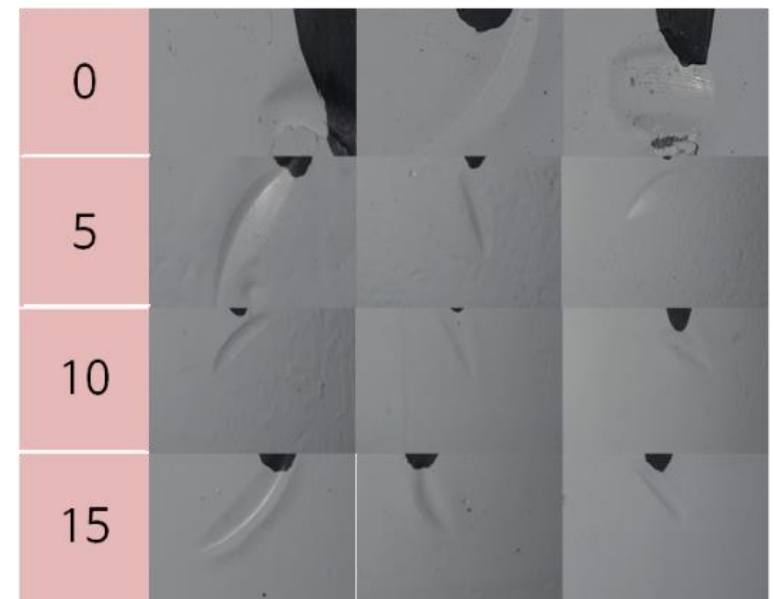

Figure 11 Impact resistance according to the mixing ratio of purple bacteria

\subsection{Viscosity}

[Figure 12] shows the viscosity according to the mixing ratio of purple bacteria as time. As the mixing ratio of purple bacteria increases, the viscosity of the paint decreases and the fall time decreases. This is thought to affect the viscosity of the paint because the purple bacteria are in liquid form.

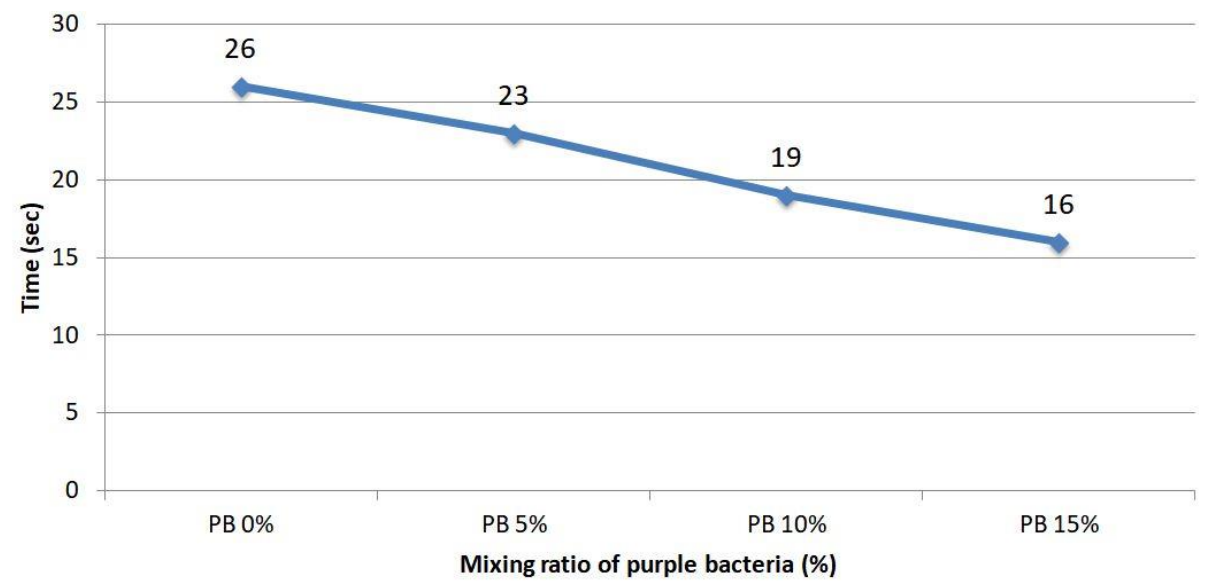

Figure 12 Viscosity according to the mixing ratio of purple bacteria

\subsection{Drying time(full hardness)}

[Figure 13] shows the drying time according to the mixing ratio of purple bacteria. As the mixing ratio of purple bacteria increases, the viscosity of the paint decreases and the drying time tends to be delayed. It is believed that since the purple bacteria are in a liquid form, the viscosity of the paint is low and the moisture is high, which affects the drying time.

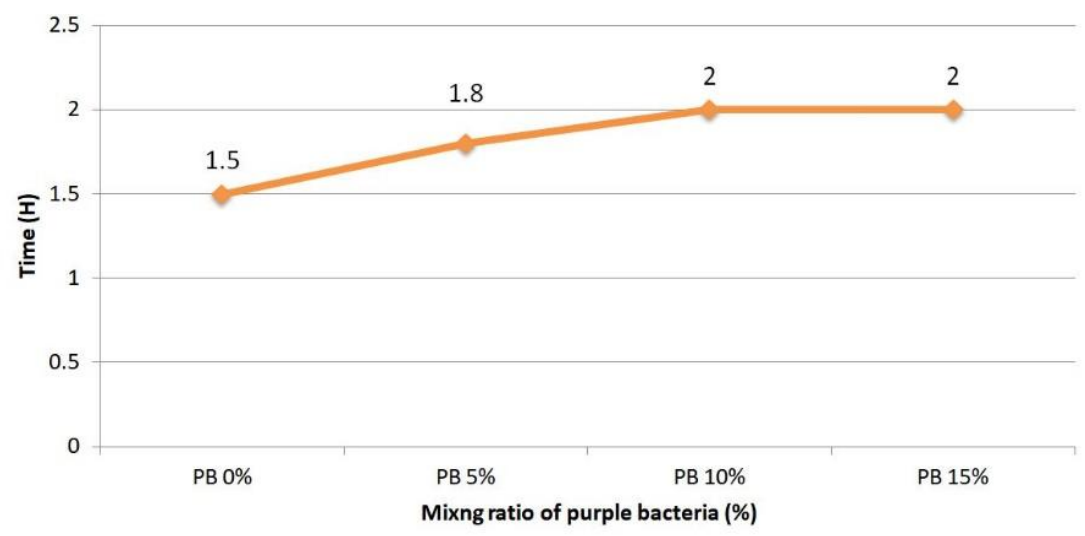

Figure 13 Drying time(full hardness) according to the mixing ratio of purple bacteria 


\section{Conclusions}

The maximum mixing ratio of paints containing purple bacteria can be up to $15 \%$, and if the workability of the paint is considered, it is judged that less than $15 \%$ of purple bacteria is appropriate. In addition, it is judged that the incorporation rate of purple bacteria increases, and when light is present, carbon dioxide adsorption performance tends to be higher than when there is no light. There was no difference in alkali resistance and impact resistance when compared to water-based paints that did not contain purple bacteria. As for the viscosity, the faster the fall time of the paint, the lower the viscosity. This is thought to affect the viscosity of the paint because the purple bacteria are in liquid form. As for the drying time, the lower the viscosity of the paint, the longer the drying time. It is thought that this affects the drying time for reasons such as viscosity. Therefore, it is judged that an aqueous paint incorporating purple bacteria can reduce carbon dioxide emissions to improve air quality and be used as a functional paint.

\section{References}

1. Joe JH. A fundamental study on the engineering properties of $\mathrm{CO}_{2}$ absorption concrete using photosynthethetic bacteria [master's thesis]. Korea National University of Transportation; 2013. 93 p.

2. Lee JM. A study on measurement and improvement of IAQ in apartment housing depending on the finishing materials used : focused on HCHO and TVOC [master's thesis]. Yonsei University; 2007. 158 p.

3. Types of microorganisms according to nutrients [Internet]. Hyunyou, Chang.; [updated 2017 March 13; cited 2019 Aug 15]. Available from: https://m.blog.naver.com/PostView.nhn?blogID=hychang5010\&logNo=220951915945

4. Pyeon SJ, Nam JS, Lim JJ, Lee SS. Properties of $\mathrm{CO}_{2}$ concentration of adsorption type matrix by dilution ratio of purple nonsulfur bacteria. Journal of the Architectural Institute of Korea. 2019 April;39(1):618619.

5. Pyeon SJ, Kim DY, Lim JJ, Lee SS. Setting time properties of cement matrix according to photosynthetic bacterial dilution ratio. Journal of the Korean Institute of Architectural Construction. 2018 November;18(2):89-90.

6. Lim JH, Jung JH, Lee GC, Yoon SJ. A study on the properties of cement mortar mixed photosynthetic bacterium. Journal of Korea Concrete Institute. 2013 May;25(1):733-734

7. Joung JH, Lee GC, Yoon SJ, Joe JH, Choi JG. Effect of partial replacement of water with photosynthetic bacteria on the Level of $\mathrm{CO}_{2}$ absorption in mortar. Journal of the Korean Institute of Architectural Construction. 2015 February;15(1):17-23

8. Kim KH. Performance and application direction of building paint. Construction technology review(ssangyong); 2004. P. 6.

9. Lim JY. Study on the manufacturing processes and characteristics of water-based paints [master's thesis]. Dongguk University; 2000. 80 p.

10. Shin ES, Kim JW. A study on the indoor air pollution levels in the classrooms at public schools in Suwon. Journal of the Korean Society for Environmental Sanitary Engineers. 2002 March; 17(1):20-27 